\title{
Buildings Materials \& Structures Based on Advanced Polymer Nanostructured Matrix
}

\author{
Rudolf Gizelter \\ The GM Association, 7 HaMada St., Herzliya Pituach 46733, Israel \\ E-mail address: rudolf194138@mail.ru
}

\section{ABSTRACT}

Development of manufacture of linear diene oligomers belonging a rubber lass with viscous liquids consistence allowed to create a new class of co glomerate lym composite materials - rubber concrete (RubCon $\left.{ }^{\circledR}\right)$. Rubber concrete is th a nced cons conal material created for last years. It is polymer concrete with a unique set o phys mechanical, chemical and technological properties which allow to obtain highly effecti ylding st vres and products on its basis.

Keywords: RubCon; butadiene rubber; natural rubber, ru $r$ industry

\section{INTRODUCTION}

Developments in civil oinee $\mathrm{hg}$ and Austrial growth have created a continual demand for building mate als itb a improved performance attributes. Polymer concretes (PC) appear to offer pos. lities for meeting these new requirements. By polymer concrete is meant a p $y$ composi th a polymer matrix and sand and rocks, like those used in Portland cG ent rete, as inclusions. Service conditions often dictate specific material require ne that he met by $\mathrm{PC}$ when several composite properties are considered sir ultane usly.

Advanc ant InPC materials have slowed over the past 25 years compared to the rate of advancements the $19 / 0 \mathrm{~s}$ and $1980 \mathrm{~s}$. The knowledge base in concrete polymer materials has $y_{\text {atur }}$ as mar oducts have been made commercially available. There are now many $\mathrm{pq}$ er-b sed const uction materials that have been shown to perform very well for their inten concrete spall repair, crack repair, concrete overlays, and precast concrete compon The cost of polymer-based systems is high relative to conventional portland cement con ete materials, and it is necessary to demonstrate the improved durability, reduced thickness/size, ability to be placed in difficult environmental conditions, and/or the fact that other non-polymer materials will not work. There are many situations for which concretepolymer materials prove to be the most appropriate materials for the intended application.

Understanding of the nature of PC is necessary for the design of the most cost-effective $\mathrm{PC}$ composites and to produce materials with desired properties.

Polymer concrete is usually used in severe conditions in industrial and public buildings as well as in transportation and hydraulic structures. The main uses are repair/ strengthening, 
and corrosion protection of concrete structures. The main advantages of polymer concrete over ordinary concrete are improved mechanical strength, low permeability, and improved chemical resistance. The main limitation is their relatively high material cost. This is why it is important to find the optimum technical/economic compromise. To solve this problem, it is necessary to formulate a reliable predictive mathematical model of polymer concrete material properties.

One of the new kinds of the structural polymer building materials created recently is rubber concrete based on polybutadiene binder (is short for RubCon). The idea of use of liquid rubber as the binder for polymer concrete was the first time put forward by Drof. $O$ .Figovsky and was patented in USA and Russia. Application of RubCon in pract i f construction allows to solve a problem of corrosion, negative influence temperatu degradation of a material at raised UV - exposure, radiation and other arvers tural a technogenic factors, to increase the between-repairs period, reliabili $y$ and du lity of buildings and structures especially at action of aggressive environy nts. It neces ry to note, that RubCon is more cheaper in comparison with other cro resistan polymer composites.

Development of manufacture of linear diene oligome onging to 1 quid rubbers class with viscous liquids consistence allowed to create an y clas f conglomerate polymer composite materials - rubber concrete (RubCon $\left.{ }^{\circledR}\right) / m b$ ber con the is the advanced constructional material created for last years. It is polymer concrete with a unique set of physical-mechanical, chemical and technological operties wh/ch allow to obtain highly effective building structures and products on its basis

RubCon contains no cement as a binder; its ma the liquid rubber family so that RubCon has properties and it is extremely resistant to aggressive chemicals, highly repellant to wat an m. remarkable compression strength. It does not exhibit the common failure-mechani ns of Conventional concrete such as cracking and flaking, freeze and thaw, sists vi rations making it an ideal pad material for pumps and compressors. Furt to water, hence arresting

The strength and rability or crete is dependent upon the variation of particles and the binder used with is ication. $\mathrm{k}$. 0 Con is applied in the same manner as conventional concrete, formula irst fr a component mixture into a liquid and then cured for 12-48 hours for harde ing. The initial der components are formulated off-site into a mixture.

The co onen ixture consists of a single component package for hot curing $\left(150{ }^{\circ} \mathrm{C}\right.$ to $180{ }^{\circ} \mathrm{C}$ ) wh shelf li of three months (in a closed container), and a two-component packag cold $\left.\quad{ }^{\circ} \mathrm{C}, 25^{\circ} \mathrm{C}\right)$ and semi-hot $\left(70{ }^{\circ} \mathrm{C}\right.$ to $\left.100{ }^{\circ} \mathrm{C}\right)$ curing with a shelf-life of six onth

The manne. $y b C O n$ is easily applied and will adhere to metal or glass reinforcements. After two days, $R u \Delta$ may be walked upon and after seven days, it is ready for work loads. With the use of spesal adhesives, RubCon can be applied over existing concrete flooring. RubCon's outstanding mechanical properties follow (Table 1). 
Table 1. Basic physical-chemical and mechanical properties of RubCon

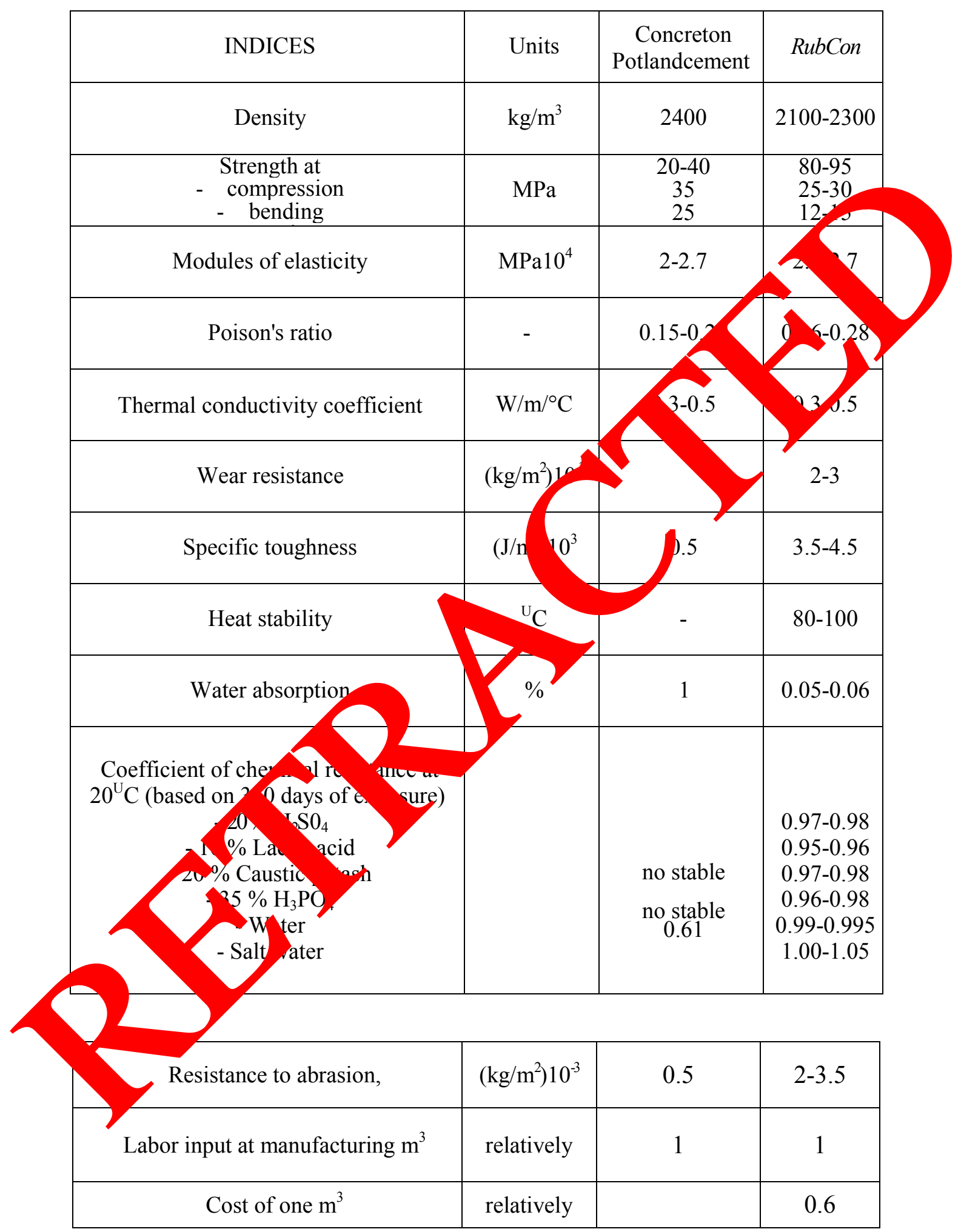


Compositions on the base of liquid rubbers are divided, according to their degree of filling, to a number of structural sub-systems including one other as "matrix + additives": liquid rubber thardening components $\rightarrow$ rubber matrix $(\mathrm{RM})$; RM+filler $\rightarrow$ rubber binder $(\mathrm{RB}) ; \mathrm{RB}+$ complimentary additives $\rightarrow$ rubber concrete (RubCon).

A very important moment in projecting of a polymeric composition is the choice of the polymer, because its chemical composition and structure determine characteristics of the created material. That is true also for RubCon, the liquid phase of which consists from rubbers with various microstructure of polymeric chain. Liquid rubbers in projected compositions are able, if acted by special accelerating systems, to be vulcanized with formation of spaco linked net polymers, the space net of which mainly determines the positive properties of ard $\mathrm{ba}$ RubCon composite.

As several studies show, the best combination of physical, cheminal, nical e parameters are exhibited by RubCon based on diene olygomers with at function oro ps hardened in presence of sulfur-acceleration system. Composites of thi ind h a nu ser of positive properties, comprising excellent characteristics in durabili resistan e, waterand chemical resistance etc.

For the correct selection of rubber for RM a complex $g^{f}$ in taken into account, comprising the capability of the siden volymer to satisfy the properties needed for the projected composite, its a arran lity and sologic suitability. Following these criteria, the selection of the polyme was carried out a nong existing kinds of liquid rubber: SKDN-NR (Russia), PBNR (Russia), blyoil 110R (Germany) and Ricon 130R (USA). All these types belong to the group of bers con prising also low-molecular hydrocarbon diene-based polymers (solvent-free liqu cre of butadiene) with a large spectrum of molecular masses and microstru These are characterized by numerous nonsaturated olefin bonds allowing easy linkage nd alm modifications. Moreover, each of them has determined and carefully antrolled icrostructure, which seriously determines the properties of liquid rubber. Ac ora selected types are rubbers wi 4-ci structure (SKDN- NR and Polyoil 110R) and rubbers with mixed microstructure $\mathrm{NI}$ anman).

On purpose of sel tion of the rid rubber involved into the mixture, the durability of

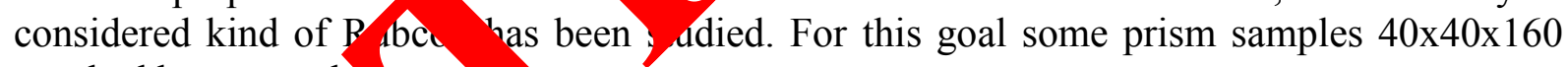
$\mathrm{mm}$ had been teste

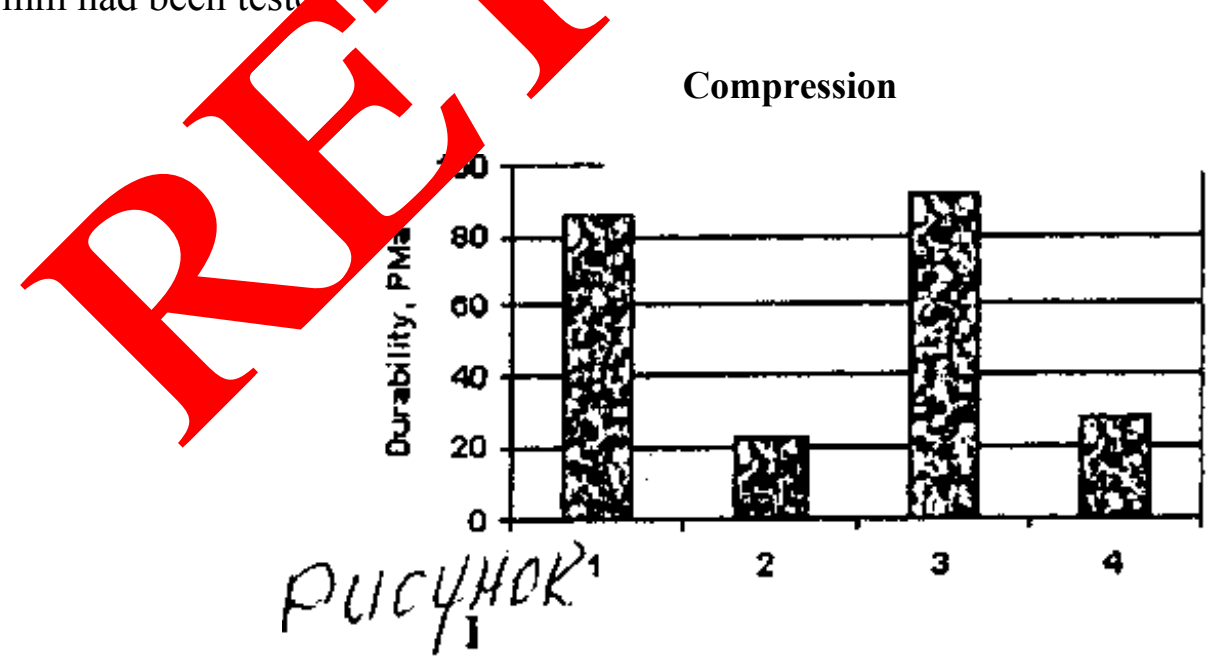

Figure 1. TValues of $\sigma c o m$ and $\sigma \mathrm{b}$ of RubCon for various rubbers. 1- PotyoilR, 2-PBNR, 3- Ricon 130R, 4-SKDN-NR. 


\section{Bending}

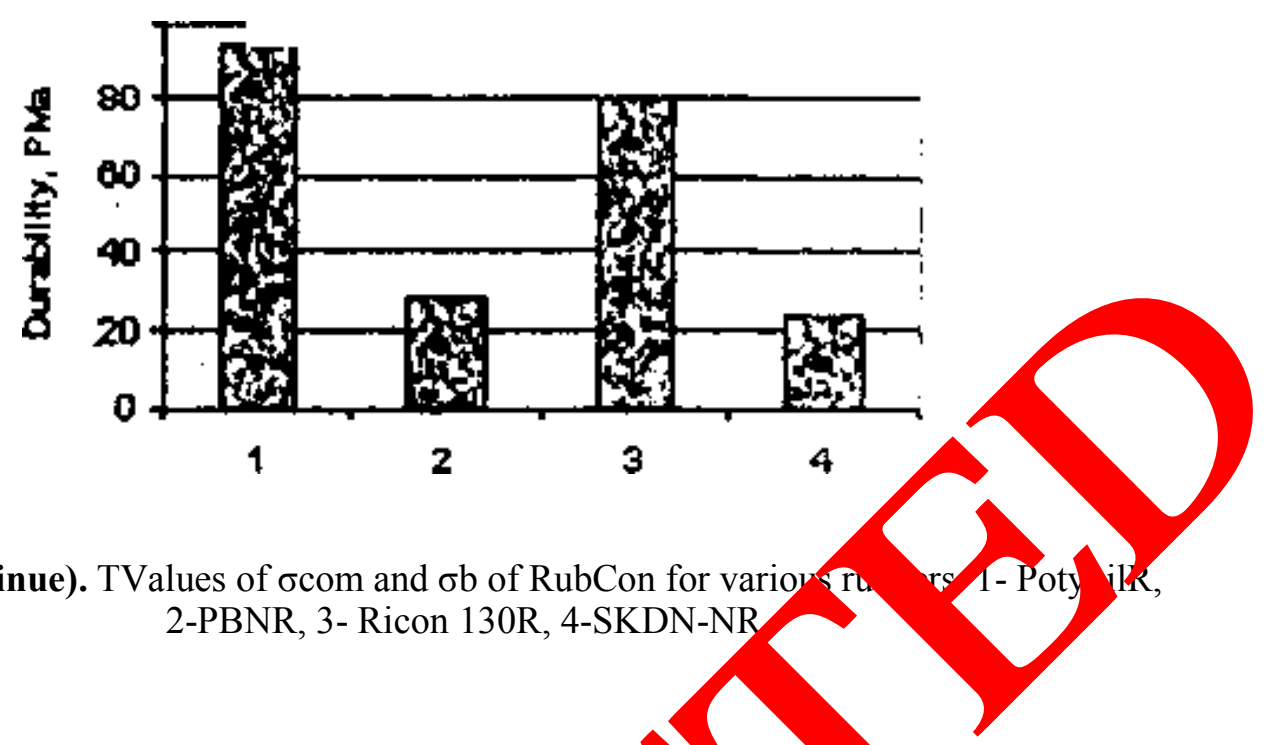

According to the results of the experiment (Figur the ma um durability against compression and bending was found for samples on te base of liquid abber PBNR ( $\sigma$ com $=$ 93.0 MPa, $\sigma \mathrm{b}=28.0 \mathrm{MPa})$ and Ricon 130R $(\sigma \mathrm{c} \mathrm{n}=94.0 \mathrm{MPa}, \sigma \mathrm{b}=26.0 \mathrm{MPa})$. Less durability was found for samples on the base of Pol $1110 \mathrm{R}($ gmacom $=84.0 \mathrm{MPa}, \sigma \mathrm{b}=$ $23.5 \mathrm{MPa})$ and SKDN-NR $(\sigma \mathrm{com}=81.00 \mathrm{MPa}, \sigma \mathrm{b}=\mathbf{\mathrm { MPa }}$

Upper values of (durability of RubCor nles on tme base of PBNR and Ricon 130Rin comparison with those of SKDN-NRand 1 lyo apare explained, in our opinion, by different molecular structures of polymeric hans $Q /$ the used olygomers. As mentioned above, rubbers SKDN-NR and P y $10 \mathrm{R}$ ch tain major amount of 1,4-cis units - to $75 \%$ of total, while in robbers with iixed hicrostry cure PBNR and Ricon 130R the content of 1,4-cis, 1,4-trans and 1,2 - Such a redistribution of the microstructure of polymeric chain is fay rable fo crease of the three-dimensional polymer induction formation period and a of dou bonds conversion. Moreover, rubbers with mixed microstructure have etter votropy that allows obtain better mixing of the components when the RubC 1 mixture is $\mathrm{p}$ ed. These factors are favorable for processes taking place in the compo tions hen they are prepared and vulcanized, that determines better durability characteristics the prodi t. However, we have to note that olygodienes of 1,4-cis structure are more-reactic able nd based on them Rubcon at the same other data have lower temp cratu, and lar ate of vulcanization.

As f lows fron mentioned above, it found to be optimal to accept linear polybutadiene olygo s or m...ed microstructure PBNR and Ricon $130 \mathrm{R}$ as the basic polymer for RMRubcon.

Since viscosity is very important parameter characterizing every liquid rubber and influencing the main physical and mechanical properties of the projected composite, it frequently determines the choice of the polymer and reasonability of its use. Industry manufactures rubbers with viscosity varied in large spectrum, e.g., for polybutadiene PBNR that is interval $(0.2,7.1) \mathrm{Pa}^{*} \mathrm{~s}$. However, there is being no data allowing estimation of viscosity of rubber useful for its employ in RubCon compositions. Obviously that as lower is the viscosity of rubber as lower is the viscosity of the obtained RubCon composition, hence there is opportunity to obtain better mixing of the components and so improve physical and 
mechanical properties of the composite or reduce the consumption of the polymer. On the other hand, rubber of low viscosity caused by large presence of molecules with polymerization degree from 3 to 6 cannot provide vulcanization net of high density that decreases durability of the composite in general. Although, if rubber with viscosity allowing formation of vulcanization net of high density meant excellent physical and mechanical characteristics of the composite, is used, that may cause increase of viscosity of all the composition. The last factor would cause increase of consumption of energy and efforts needed for the preparation of the mixture without gaming better properties or make the mixture loose and bad for treatment, with worse resulting properties. The comios of experiments have carried out for the evaluation of the value of viscosity of rub or allo $g$ the needed varied parameter has been viscosity, and the measured function the RubC durability against compression and bending. The experiment used ryber NR wi viscosity (Pa*s.): $0.4 ; 0.6 ; 0.8 ; 1.0 ; 1.2 ; 1.4 ; 1.6 ; 1.8 ; 2.0 ; 2.2$. The regr ssion anal of ne obtained results allowed deduction of mathematical models ade ately escrib of the correlation of durability of the samples against compression and be fin.

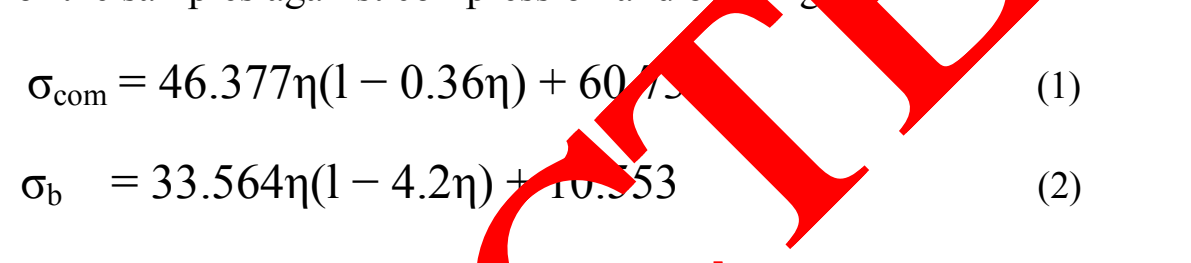

where $\sigma_{\text {com }}$ is the durability of PBNR - RubCon san les against ompression, MPa; $\sigma_{\mathrm{b}}$ is that against bending; $\eta$ is the rubber viscosity, $\mathrm{Pa}^{*} \mathrm{~s}$.

Based on these results, (me may cor ${ }^{-1}{ }_{1}$ de that of optimal viscosity of lowmolecular polybutadiene with mixed micros un involved into the RubCon mixture, is in interval from 1.1 to $1.7 \mathrm{Pax}$ s. The further stu ies $\mathrm{mp}$ yed rubber with viscosity $1.5 \mathrm{~Pa}^{*} \mathrm{~s}$.

It is obvious that the amo of lov molecular rubber in RubCon composition permanently changes with the $k$ id, a ersion amount of the filler, number and granular composition of filters etc. L ver the evaluation of optimal content of rubber in the composition is possible or an stage or the composition projecting. For the solution of this problem an experi thas bee arvied out. Variable quantity was the amount of lowmolecular rubber ip the nposition (PBNR); the goal functions were compression and bending strength the composition and technology of sample preparation have been the same hat in selection of the kind of rubber. The regression analysis of obtained results prov ader anematical models:

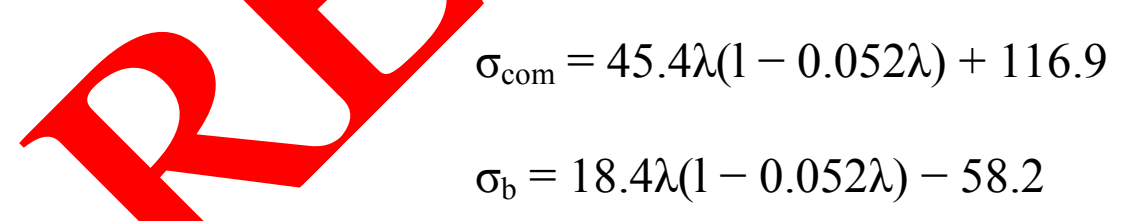

where $\lambda$ is ne content of rubber for various amount of rubber.

The analysis of obtained data allows conclusion that the optimal content of rubber in the composition is from 8.5 to 10.5 mass. \%. The content of rubber less than 8.5 mass \% causes discontinuance of the film structure of the polymeric matrix and pore formation, while more 10.5 mass \% provides unstable inhomogeneous structure of the mixture during formation.

Liquid polybutadienes without functional groups may be vulcanized on double bonds of the diene part of the polymeric chain in presence sulfur-accelerating, Red-Ox or peroxide system. However, the sulfur-accelerating system only is being able to provide the obtainment 
of maximal values of durability. Sulfur has also other advantages - low price, availability etc. The amount of involved sulfur in the system depends on desired properties of the product. For hard RubCon that is 47-55 mass parts per 100 mass parts of rubber.

The rising of the rate of chemical reactions between sulfur and rubber, acceleration of the vulcanization process and reduction of its temperature are gained by involving of special accelerators. The use of a few of accelerators may improve the vulcanization process because of their mutual activization. Two accelerators were used: tetramethyl-thiuram-disulfide (thiurarn-DR) and captaxR. They act mutually and thus improve the vulcanization process and the resulting properties of RubCon.

The mentioned above suggestion has been tried in two-phase experiment, variable parameters were the amounts of accelerators, and the value of RubC durability the function.

It has been found from the experience that the maximal value of $\mathrm{AbCon} d \mathrm{u}$ ilit is obtained at the captax content 0.05 mass. $\%$, while thiuram-D - 0.35 qss. \% The ma mum durability against compression has been found at maximum nto 1 thiur $\mathrm{A}-\mathrm{D}$ and moderate content of captax.

Regression analysis of the experiment results provides 'ow equations:

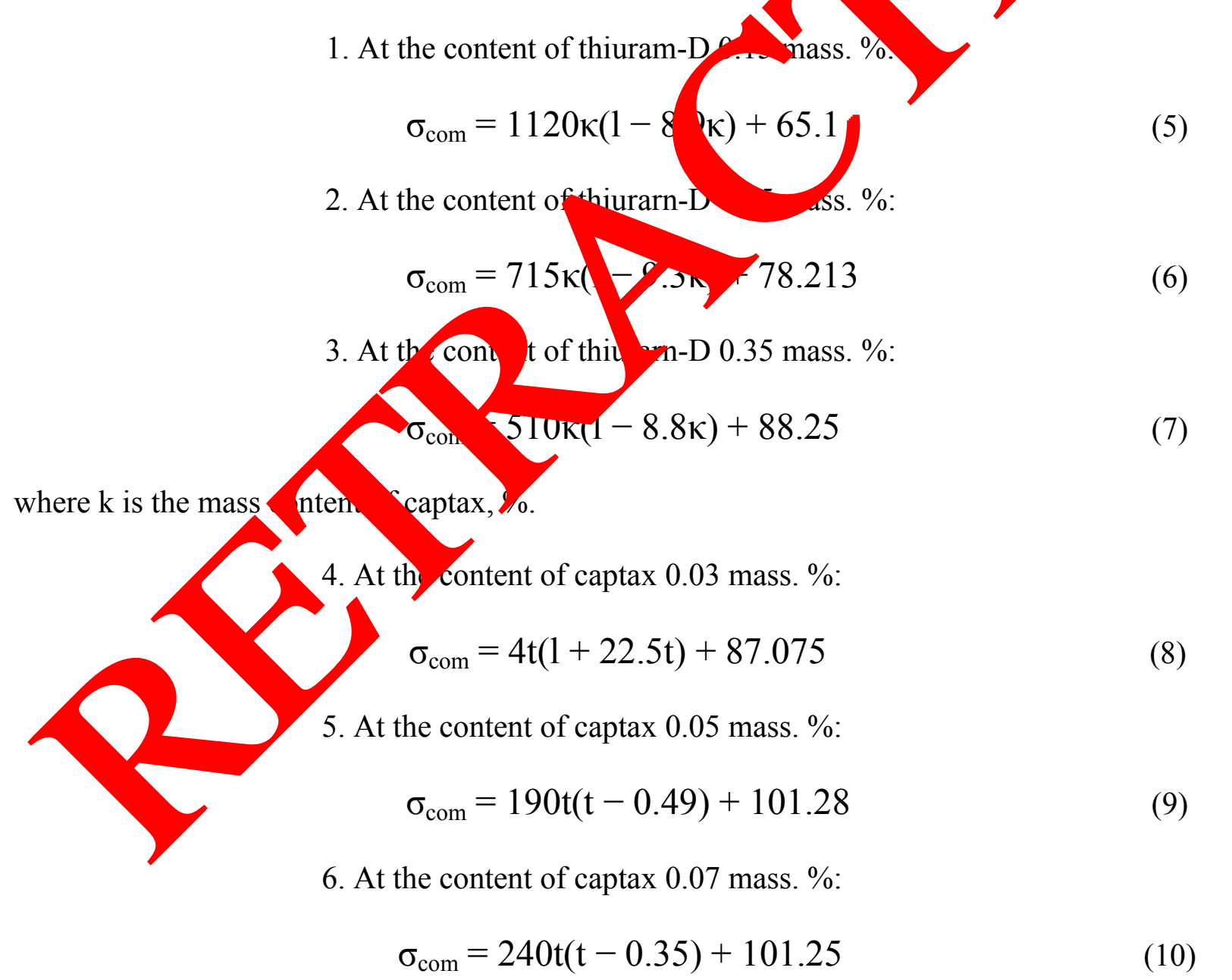

where this the mass content of thiurarn-D (\%). 
The general correlation equation:

$$
\sigma_{\mathrm{com}}=173.3 \mathrm{t}(\mathrm{t}-0.186)-7042 \kappa(\kappa-0.122)+300 \mathrm{t} \kappa+73.28
$$

The decrease of RubCon durability at the captax content is less 0.05 mass. \% is caused by the violation of accelerators complex action and appearance the chemically free rubber. The content values more $0.05 \%$ causes excess of captax and related decrease of durability. The increase of product durability, when the content of thiuiam-D closes $0.45 \%$, is caused by gas deliverance and pore formation in the composite volume. The hypothesis of aitive influence of captax on the durability because of kinetic factor has been ch-cked in described below experiment.

Series of RubCon samples have prepared. The content of main accelerators) has been the same. The first composition used accelerator thiurarn-D ap ax, the second one -thiuiam-D only. After the temperature gaining $120 \%$ in exo rrmal gime, each $60-\mathrm{mm}$. three prism samples $(40 \times 40 \times 160 \mathrm{~mm})$ have be be emoves from the camera and tested against compression.

The analysis of curves I and 2 (Figure 2) shows that in or of the se nd accelerator into the composition improves the kinetics of vulcanizatic

- increase of the induction period of vulcanization $(A 3)$ when the struy are formed;

- reduction of the main period of vulcanization whe the optimum gained;

- increase of the time duration when the optimum $\mathrm{s}$

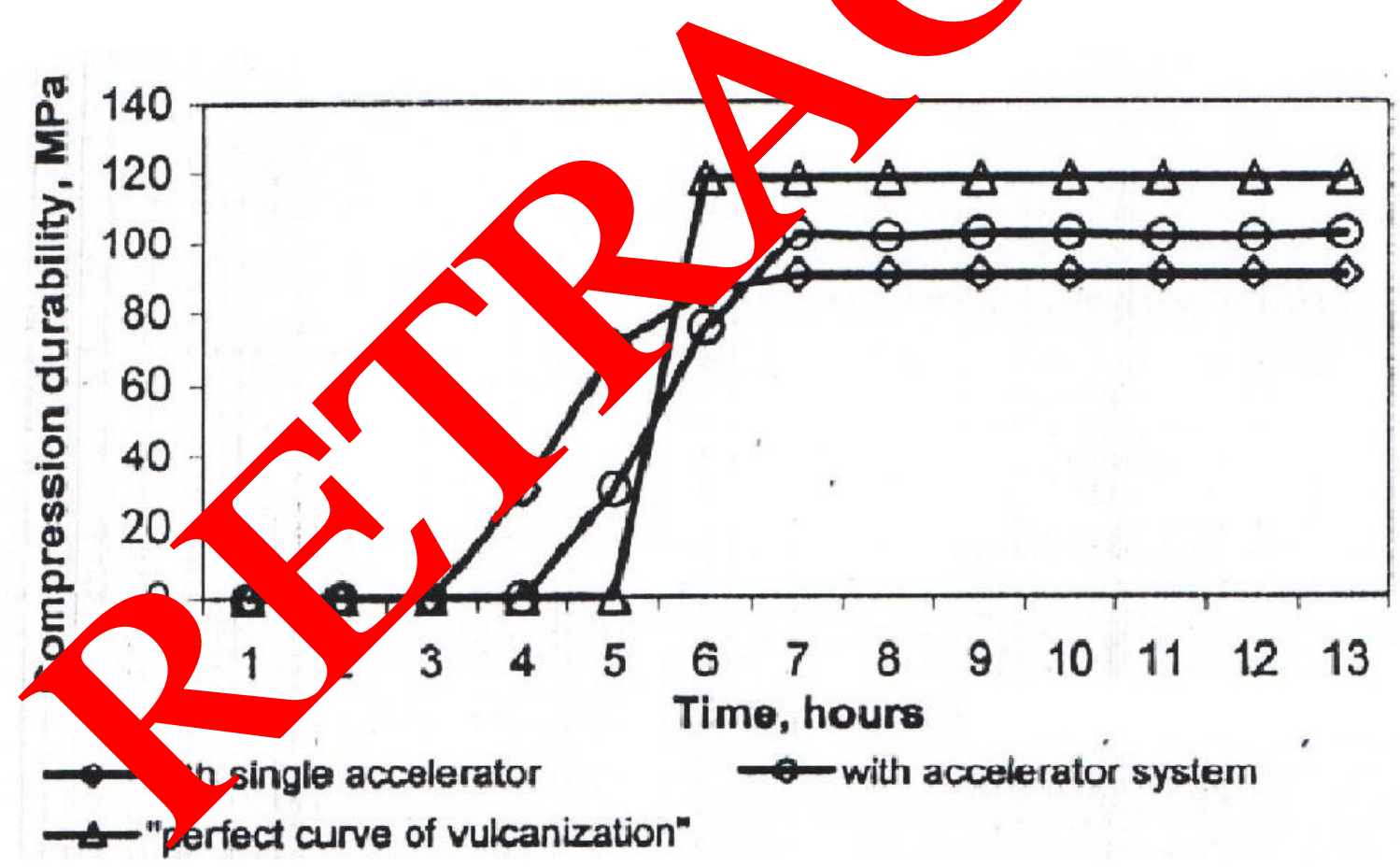

Figure 2. Kinetic curves of compression durability gainig. 1 - with single accelerator, 2 - with accelerator system, 3 - "perfect curve" of vulcanization.

The change of parameters of vulcanization kinetics found in the experience allowed more order in the composite structure, reduction of the number of dislocations and, 
consequently, improvement of mechanical characteristics of RubCon. Let us note that the optimum content of the components in the system with additive action of accelerators for rubber of the same kind is constant; for PBNR it is 7 parts of thiurarn-D per I part of captax.

Based on analysis of references, it had been found that organic accelerators of vulcanizations are especially active in presence of several oxides and hydroxides of metals (vulcanization activators) like zinc, lead, magnesium, calcium, cadmium, bismuth and their combinations. The most widespread activator used in technology of rubber composition treatment is zinc oxide (zinc white). In comparison with other activators it is cheaper and largely used in chemical industry as law material. Based on the mentioned above, zinn-xide was accepted as RM-vulcanization activator, and its optimal content in ie Ru. composition was estimated as 10-20 mass parts per 100 mass parts of rubber. $Y$ lving of mass, \% calcium-containing component $(\mathrm{CaO})$ allows reduction of gas de ${ }^{1}$ vera and po formation during vulcanization. The evaluation of RM optimal composit on has can out oy variation of three parameters: amount of sulfur (s), amount of accel tor $(t)$ moun of the activator (z) in RM, whereas the efficiency functions are compress $i$ anding s ength.

The amount of rubber PBN in the experiment was $100 \mathrm{~m}$ s parts; cont $\mathrm{nt}$ of other components: $\mathrm{CaO}$ (5 mass parts), filler (87.5 mass parts), s 1000 mass $\mathrm{s}$ s) and coarse aggregate (680 mass parts). The regression analysis of rea of $t$ xperiment provided the following equations:

1. For samples tested against compression:

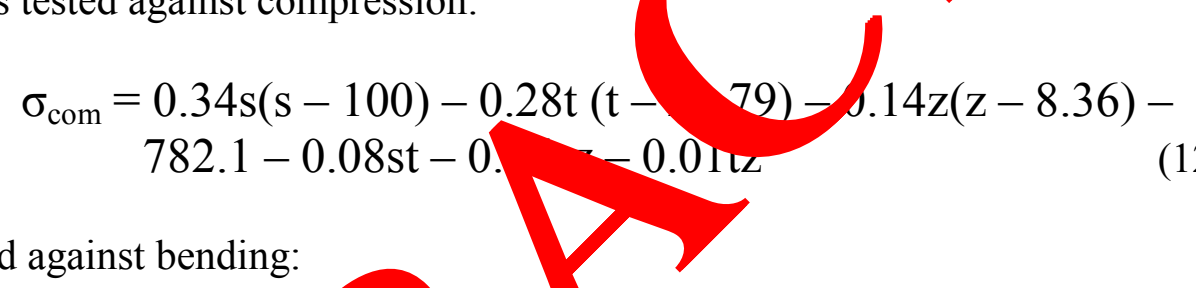

2. Those tested against bending:

\begin{tabular}{|c|c|c|c|c|c|}
\hline \\
\hline Bending
\end{tabular}

It has been found from the results of experience that the most influence on the change of durability is of sulfur and vulcanization activator, while that of the accelerator system is less important. The increase of sulfur content increases the durability against compression but decrease that against bending. Interactions sulfur-accelerator and sulfur-activator influence 
similarly. The compositions of RubCon destined for operations under compression or bending charges, respectively, are given in the Table 2.

Control tests of RubCon samples prepared according to the foregoing recommendations provided the following values of strength: at compression $105 \mathrm{MPa}$, at bending- $31 \mathrm{MPa}$.

Figure 3.1. Draft of testing gadget: 1- sample of RubCon; 2- calibrated rods; 3- plate: 4centering bar. Characteristic pressure - deformation relationship is shown in Figure 3.

\section{Compression stress, $\mathrm{MPa}$}

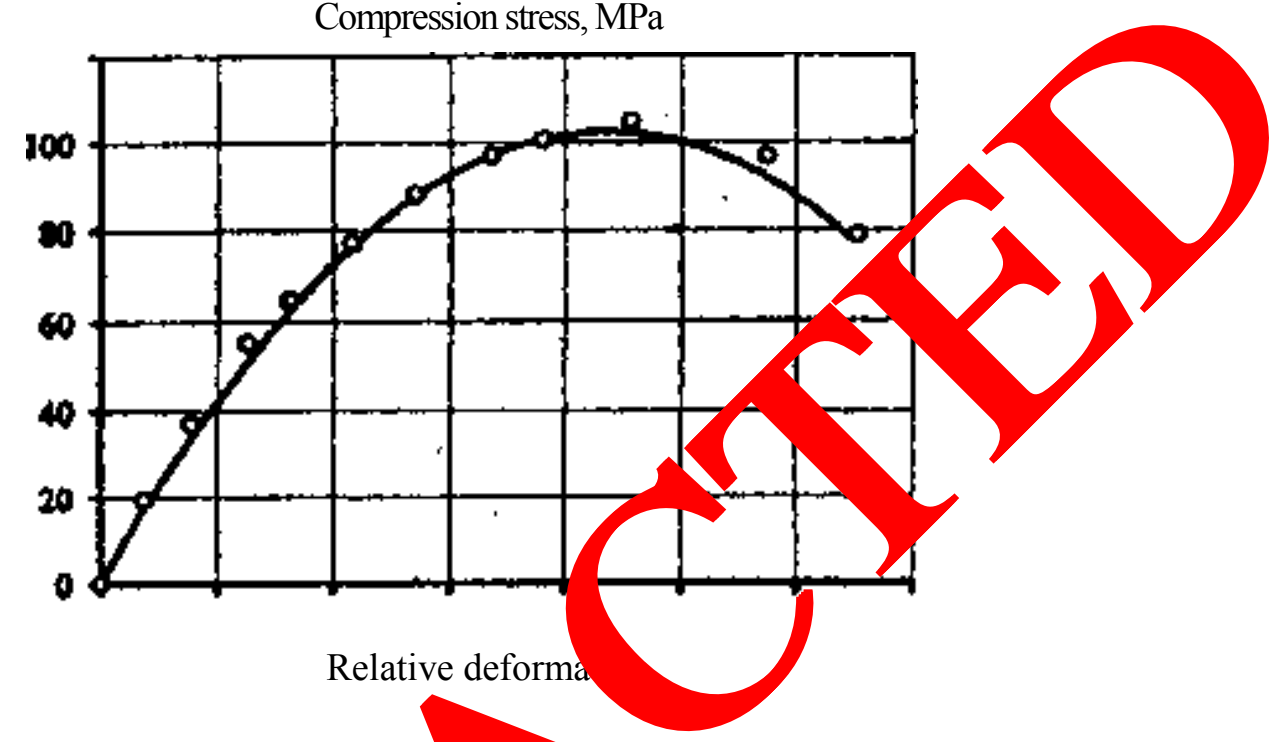

Figure 3. Relationship between relative Ton of $R u b C o n$ and compressive stress.

Analytical form of this de ende may b yabmitted as:

Let $\mathrm{v}=\sigma / \sigma_{R} ; \eta=\varepsilon /\left\langle k=\Delta \quad\left\langle\sigma_{R}\right.\right.$. On/ne experimental base it is believed that dependence $v=f(k \eta)$ looks square $\mathrm{p}$ bola $v=k \eta-\eta^{2}$, where $\sigma, \varepsilon$ are the current values of compression ress a deform, cons correspondingly, $\sigma_{R}, \varepsilon_{R}$ - coordinates of the diagram top, $k$ - the fa decrivin elastic-plastic properties of RubCon. Then,

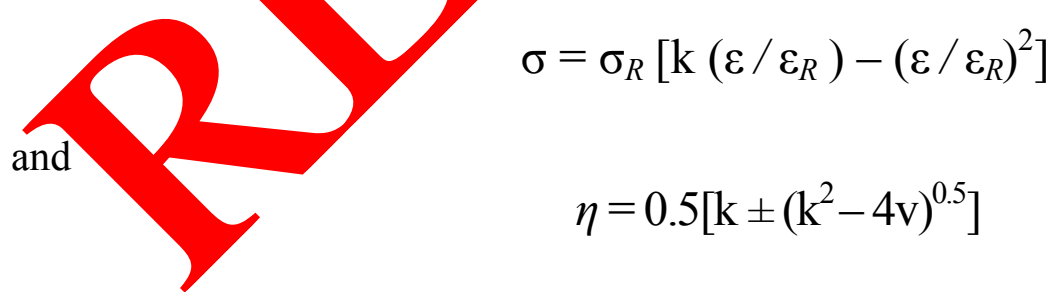

For the experiment performance the test RubCon samples in size $40 \times 40 \times 160 \mathrm{~mm}$. were prepared. Tests were carried out in the special chamber, in the temperature range $-80{ }^{\circ} \mathrm{C}$ $\pm+80^{\circ} \mathrm{C}$ appropriated to real operation conditions of the material. During experiments the stress-strain state of samples was determined depending on temperature of environment. In particular, the changes of the module of elasticity, ultimate strength at compression and the appropriate ultimate deformations of a material at influence of temperature were determined in comparison with the similar values obtained at test of control samples at room temperature. 
Results of experiments at negative temperature range are illustrated in Figure 4. It is possible to see, that at the maximal negative temperature $-80^{\circ} \mathrm{C}$ the ultimate relative strain decreases on the average $14 \%$ in comparison with control values, and ultimate strength at compression and the module of elasticity, on the contrary, are increased on 19 and $35 \%$ correspondingly. It is necessary to note thus, that change of ultimate deformations linearly depends on temperature.

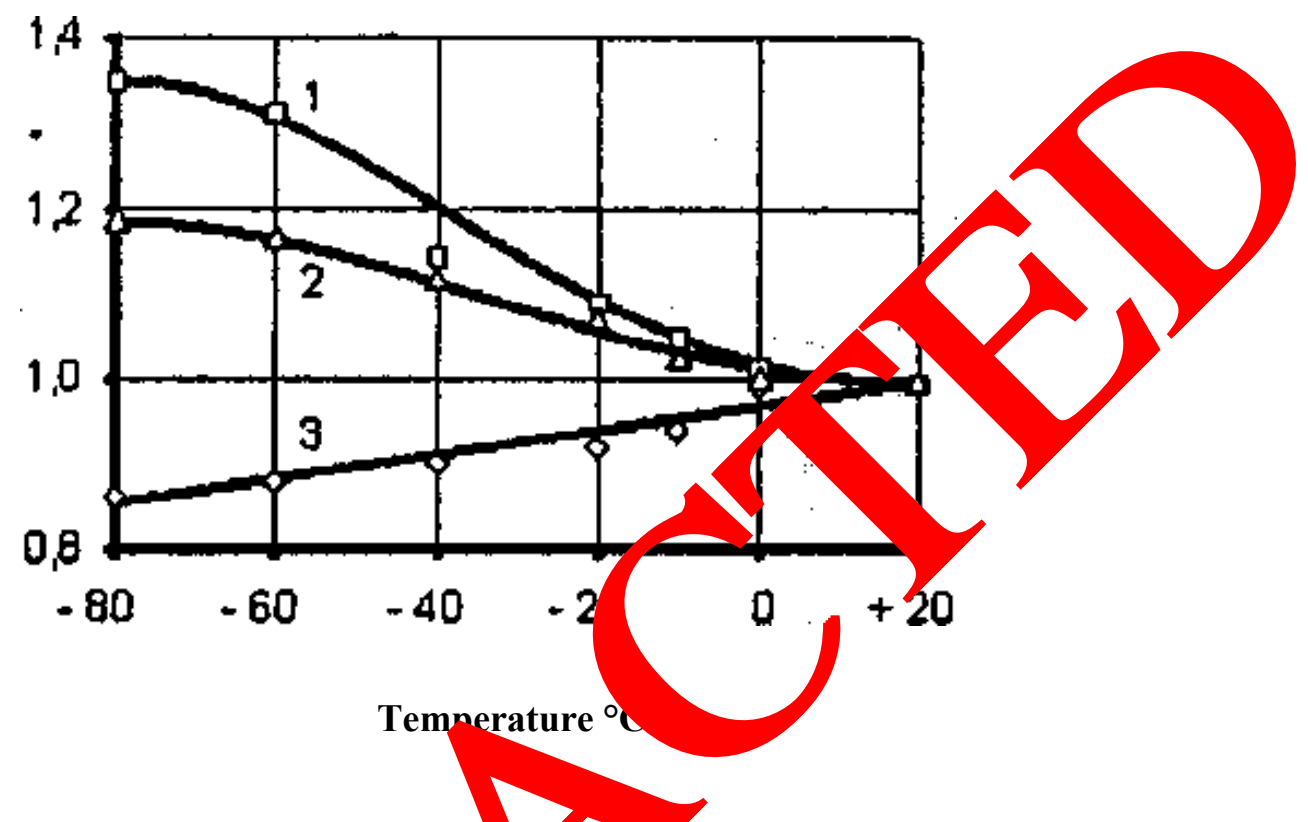

Figure 4. Influence of negative temperatures on th ratio the module of elasticity (1), ultimate compression strength (2) and ult deform ions at compression (3) to the similar values obtained at test if con 1 RubCo amples at room temperature.

We have shown microstru of RubCon has elastic, elastic - plastic and viscous phases. The amoup of st in th composite is less in comparison with others and consequently deforoility $\mathrm{ubCon}$ at action a long-term and a short-term loadings in the greater degree $s$ determined by astic and elastic - plastic deformations.

Increa of th $\mathrm{xu}^{\mathrm{h}} \mathrm{Con}$ strength and the module of elasticity at compression and decrease of its nate de rmations at negative temperatures can be explain by increase of a viscoy visu $\mathrm{v}$ and partial transformation of an elastic - plastic phase of a composite in $y$ stic. he increa of an elastic phase results to embitterment of composite and by that to chan.

\section{CONCLUSIONS}

- Experimental - theoretical investigation of central and eccentrically compressed short elements from RubCon (without buckling) is performed. The design procedure, which takes into account unlineary relationship between stress and strain and the valid diagram of deformation at uniaxial compression, is carried out on this base. 
- The carried out researches of a new kind of polymeric concrete in a wide temperature range at action of compressive loading have shown an essential influence of the temperature environment on RubCon stress-strain state. Experimentally obtained temperature coefficients of strength and deformation characteristics of the material will allow to design load bearing and protecting structures in an operational temperatures rang.

- The increase of the particle size of coarse aggregate at constant reinforcement ratio results in decrease of RubCon compression, tensile and bending strength.

- Continuously reinforced RubCon has high compression, tensile and bending strength. Producing of steel fibers from tire cord is the way of tire industry wastes recyclin

- Creep deformation of rubber concretes has damping character; RubCom non-line stress - strain relationship; The mathematical model of creep deform ons a ong-tir e compressive loading agrees well with experimental results and can be $p$ at in basis de gn of RubCon load bearing structures;

- RubCon keeps high strength at complex influence of an ggressi anviro ment and external loading. Steel fibrous RubCon is creep resisting of ial; coeft $/$ of creep at compressive load $\mathrm{k} \ll \mathrm{r}=0.75$.

- Maritime Structures (pilings, docks and other exp sed suctures)

- Bridge Expansion Joints Bridge Deck Overlays

- $\quad$ Repairs Made to Load Bearing Supports

\section{References}

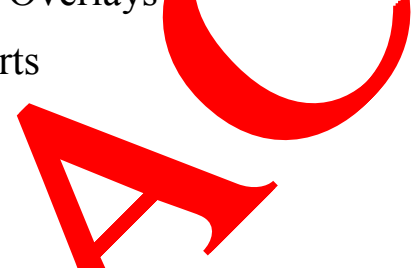

[1] O. Figovsky, D. Beilin, Ady ncea plymer oncretes and Compounds. CRS Press, N.Y. 2013, pages 267.

[2] O. Figovsky, D. Beili 1, A.Ley Recent Patents on Corrosion Science 3(1) (2013) 22-26.

[3] O. Figovsky, D eyilin, International Letters of Chemistry, Physics and Astronomy o(1) (2013) lo 09.

[4] T. Bors Murial Letters 62 (2008) 1382-1384

[5] T. Pmowski, ernat onal Letters of Chemistry, Physics and Astronomy 2 (2012) 1-6.

[6] Bor uski, T. orowski, International Letters of Chemistry, Physics and Astronomy 4 